\title{
Stimulus discriminability and conditioning-history effects on response summation
}

\author{
DONALD MELTZER and PATRICIA A. BURGER \\ Southern Illinois University, Carbondale, Illinois
}

\begin{abstract}
Two groups of rats were extinguished for responding when neither light nor tone was on. During the first part of the experiment, the subjects in Group 1 were reinforced for responding during a compound light-tone stimulus, and the subjects in Group 2 were reinforced for responding when either light or tone was on. During the second part of the experiment, the subjects were reinforced in the presence of a light-tone compound, light alone, or tone alone. They responded at higher rates during the light-tone compound than during either of the other stimuli. This constituted response summation, and because there was no difference between the groups, it was concluded that response summation did not depend on a history of reinforced responding to the component stimuli.
\end{abstract}

Several recent reviews (e.g., Kehoe \& Gormezano, 1980; Weiss, 1978) have described the variables affecting the phenomenon of response summation. In summation studies, a subject is presented with two different discriminative stimuli on different trials. Each of these stimuli is followed by the same unconditioned stimulus (UCS) in classical conditioning (Konorski, 1948; Pavlov, 1927) or allows the subject to respond for the same reinforcement in instrumental conditioning. For example, one trial may consist of a light conditioned stimulus (CS) followed by a food UCS; another trial may consist of a tone CS followed by the same food UCS. Response summation is shown when the simultaneous presentation of the two CSs results in a stronger response than the presentation of either CS by itself. Summation has been shown with operant conditioning procedures regardless of whether the stimuli were all presented during extinction (e.g., Weiss, 1964) or whether the test for summation was conducted during conditioning (e.g., Meltzer \& Freeman, 1971).

The studies in which summation of operant responses has been shown are consistent with the hypothesis proposed by Weiss (1978). He explained summation as the result of an additive process based on the response tendencies and incentive properties associated with the different discriminative stimuli. However, no data exist that indicate that prior conditioning to respond to the two stimuli is always essential for the development of response summation. Consider a group of subjects that was reinforced for

Donald Meltzer is with the Department of Psychology, Southern Illinois University, Carbondale, Illinois 62901. Patricia A. Burger is now at the University of North Dakota School of Medicine, Grand Forks, North Dakota 58202. responding only when a light-tone compound $(L+T)$ was present and was never reinforced when both light and tone were off $(\overline{\mathrm{L}}+\overline{\mathrm{T}})$. Compare them with a second group of subjects in which responses were reinforced either when the light was present and the tone was off $(\mathrm{L}+\overline{\mathrm{T}})$ or when the tone was present and the light was off $(\overline{\mathrm{L}}+\mathrm{T})$, but never when both light and tone were off $(\overline{\mathrm{L}}+\overline{\mathrm{T}})$.

Summation has usually been demonstrated by first reinforcing the animals for responding to $\mathrm{L}+\mathrm{T}$ and $\overline{\mathrm{L}}+\mathrm{T}$, as in the latter group. Only after that stage of the experiment has the $\mathrm{L}+\mathrm{T}$ compound been introduced and response rates during $L+T, L+\bar{T}$, and $\overline{\mathrm{L}}+\mathrm{T}$ been compared. Again, Weiss (1978) suggested that summation is the result of an additive process affecting the preexisting response tendencies and incentive properties of the $\mathrm{L}+\overline{\mathrm{T}}$ and $\overline{\mathrm{L}}+\mathrm{T}$ stimuli. However, summation may not depend on a prior history of reinforcement during the components of the stimulus producing response summation. It might not matter which stimulus, or stimuli, the subjects were conditioned to respond to in the first stage of the experiment. Response summation may not be the result of conditioning history but, rather, an outcome of current discriminations.

\section{METHOD}

\section{Subjects}

Sixteen 120-day-old rats served as subjects. They were on a 23-h water-deprivation schedule and were given free access to water for $15 \mathrm{~min}$ following each experimental session. Experimental sessions were scheduled 5 day/week.

\section{Apparatus}

The experimental chamber was manufactured by Lehigh Valley Electronics, Inc., (Model 1316) and was equipped with one bar, located approximately $2.8 \mathrm{~cm}$ above the floor and $3.8 \mathrm{~cm}$ from the 
left wall. There was a small pilot light approximately $2.5 \mathrm{~cm}$ above the bar. A .03-cc dipper was mounted at the base of the front wall, midway between the two bars. The chamber was completely dark when the pilot lights were off. When both lights were on, the illumination was $9.04 \mathrm{~mL}$ when measured with a light meter facing the front wall at a distance of $5.0 \mathrm{~cm}$ behind either bar. The ambient noise level produced by the blower was $63 \mathrm{~dB}$, and the auditory stimulus used in the experiment was a $714-\mathrm{Hz}$ tone that increased the noise level by $4 \mathrm{~dB}$.

\section{Procedure}

All subjects were shaped to press the bar and drink the water reinforcement during the first 2 days of the experiment. The subjects were then divided into two groups, with eight rats in each.

The subjects in Group 1 learned a discrimination in which an extinction schedule was in effect during $\bar{L}+\bar{T}$ and a variable-interval reinforcement schedule was in effect during $L+T$. A session always began with an extinction component, which lasted for a mean of $30 \mathrm{sec}$. That was followed by the $\mathrm{L}+\mathrm{T}$ discriminative stimulus, which lasted for a mean of $20 \mathrm{sec}$. When reinforcement became available, there was no stimulus change until the rat pressed the bar. At that time, the dipper operated, both the light and the tone went off, and the extinction schedule was reinstituted. The alternation of extinction and discriminative stimuli continued until the subject had earned 30 reinforcements.

After 12 sessions, the procedure was changed. $\overline{\mathrm{L}}+\overline{\mathrm{T}}$ was still the stimulus during the extinction intervals. However, $\mathrm{L}+\mathrm{T}$ was present during 10 of the 30 reinforcement intervals in each session. $\overline{\mathrm{L}}+\mathrm{T}$ was present during another 10 intervals, and $\mathrm{L}+\mathrm{T}$ was present during the remaining 10 intervals. This procedure continued for 8 sessions.

The subjects in Group 2 were exposed to the same alternation of extinction and reinforcement intervals, which still had mean durations of 30 and $20 \mathrm{sec}$, respectively. However, the discriminative stimulus used during the first 12 sessions was different. Fifteen of the 30 presentations of a discriminative stimulus consisted of $\mathrm{L}+\overline{\mathrm{T}}$, whereas the discriminative stimulus during the other 15 intervals was $\overline{\mathrm{L}}+\mathrm{T} . \overline{\mathrm{L}}+\overline{\mathrm{T}}$ was the extinction condition.

The procedure was changed during the next 8 sessions so that three different discriminative stimuli were used. $\mathrm{L}+\overline{\mathrm{T}}$ was on during 10 reinforcement intervals, $\overline{\mathrm{L}}+\mathrm{T}$ during another 10 reinforcement intervals, and $\mathrm{L}+\mathrm{T}$ during the remaining 10 intervals. Thus, the discriminative stimuli experienced by the subjects in the two groups were different during the first 12 sessions but were identical during the last 8 .

\section{RESULTS}

The data from the first 12 sessions were analyzed to see if there was any difference between the rates at which the two groups responded during reinforcement and extinction intervals. Because the subjects in Group 2 had two different discriminative stimuli (i.e., either $\mathrm{L}+\overline{\mathrm{T}}$ or $\overline{\mathrm{L}}+\mathrm{T}$ ), whereas the subjects in Group 1 had only one $(\mathrm{L}+\mathrm{T})$, the analysis compared mean response rates during reinforcement intervals with mean response rates during extinction intervals. Rates during the presence of the different discriminative stimuli used in Group 2 were not separated. Response rates during these sessions are shown in Figure 1.

There were no significant differences between the two groups or over days. However, the subjects responded at significantly higher rates during the discriminative stimuli than during the extinction stimulus $[F(1,14)=111.56, p<.01]$. In addition, the dif-

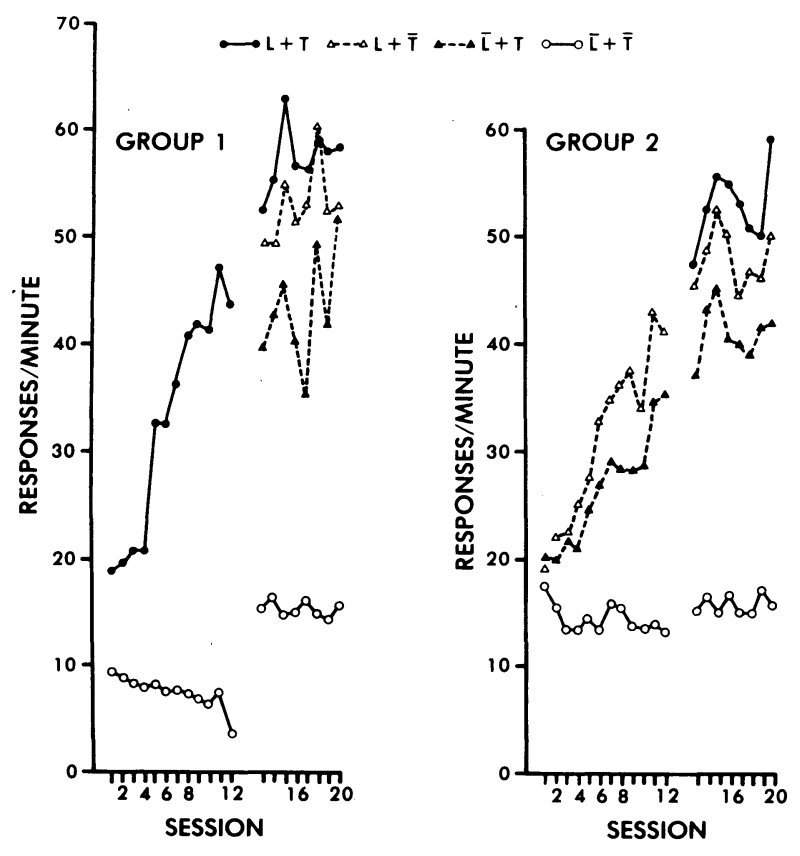

Figure 1. Mean response rates of the subjects in each group are shown above. Rates during every stimulus condition in both parts of the experiment are included.

ference between rates was greater for the subjects in Group 1 than for the subjects in Group $2[F(1,14)=$ $8.25, \mathrm{p}<.05]$. A test of simple main effects showed that there was no significant difference between the rates at which the two groups responded during discriminative stimuli but that the difference between their rates during the extinction stimulus was significant.

Another set of analyses was performed to see if the subjects in Group 1 responded at a higher rate during $\mathrm{L}+\mathrm{T}$ than did the subjects in Group 2 during $\mathrm{L}+\overline{\mathrm{T}}$. There was no significant difference. A similar analysis compared the response rates of Group 1 subjects during $\mathrm{L}+\mathrm{T}$ with the response rates of Group 2 subjects during $\bar{L}+T$. Once again, there was no significant difference.

The stimuli were changed in Session 13 so that the subjects in each group now had the same three discriminative stimuli, $\mathrm{L}+\overline{\mathrm{T}}, \overline{\mathrm{L}}+\mathrm{T}$, and $\mathrm{L}+\mathrm{T}$. To determine whether the introduction of new stimuli at this time affected response rates to the stimuli that had been used in the first part of the experiment, two analyses were performed. The response rates of the Group 1 subjects during $\mathrm{L}+\mathrm{T}$ and $\overline{\mathrm{L}}+\overline{\mathrm{T}}$ in Session 12 were compared with their rates during the same stimuli in Session 13. As expected, they responded at significantly higher rates during $\mathrm{L}+\mathrm{T}$ than during $\overline{\mathrm{L}}+\overline{\mathrm{T}}[\mathrm{F}(1,7)=81.27, \mathrm{p}<.01]$, but the increase in response rates during Session 13, which can be seen in Figure 1, was also significant $[F(1,7)=$ $9.72, p<.05]$. The interaction of session and stimulus was not significant. A similar analysis examined 
the response rates of the Group 2 subjects during Sessions 12 and 13. The rate difference during the three stimuli were significant $[F(2,14)=44.40, p<.01]$, and a Tukey HSD test showed the differences between $\mathrm{L}+\overline{\mathrm{T}}$ and $\overline{\mathrm{L}}+\overline{\mathrm{T}}$ rates, and the differences between $\overline{\mathrm{L}}+\mathrm{T}$, and $\overline{\mathrm{L}}+\overline{\mathrm{T}}$ rates, to be significant at the .01 level. The difference between $\overline{\mathrm{L}}+\mathrm{T}$ and $\mathrm{L}+\overline{\mathrm{T}}$ rates was not significant.

The major question was whether the subjects in both groups would show response summation during the second part of the study. Therefore, the data from the last eight sessions were analyzed by comparing each subject's response rate during $L+T$ with its higher rate during either $\mathrm{L}+\overline{\mathrm{T}}$ or $\overline{\mathrm{L}}+\mathrm{T}$. Summation was defined as a higher rate during $\mathrm{L}+\mathrm{T}$ than during either of the other two stimuli. The analysis showed that the subjects in both groups responded at a higher rate during $\mathrm{L}+\mathrm{T}$. Mean rates during $\mathrm{L}+\mathrm{T}$ were higher during every day of testing for subjects in both groups. The difference between $\mathrm{L}+\mathrm{T}$ response rate and the next highest rate in either discriminative stimulus was significant $[\mathrm{F}(1,14)=17.71, \mathrm{p}<.01]$, but there were no other significant main effects or interactions.

Because the rates of the two groups during extinction intervals were different during the first phase of the experiment, a second analysis that examined response rates during each of the four stimulus conditions over the eight test sessions was performed. There was no significant difference between groups, and no significant interaction of groups with any other variable. There was neither a significant effect of sessions nor a significant interaction of sessions with any other variable. The subjects did respond at significantly different rates during the different stimuli $[F(3,43)=86.97$, $\mathrm{p}<.01]$, as shown in Figure 1. An HSD procedure was used to compare mean response rates during the stimuli, and it showed that rates were significantly higher $(p<.01)$ during each of the stimulus conditions associated with reinforcement than during $\overline{\mathrm{L}}+\overline{\mathrm{T}}$. In addition, rates during the $\mathrm{L}+\mathrm{T}$ condition were significantly higher than rates during either $\overline{\mathrm{L}}+\mathrm{T}$ or $\mathrm{L}+\overline{\mathrm{T}}(\mathrm{p}<.01)$, which provided another demonstration of response summation. The subjects also responded at significantly higher rates during $\mathrm{L}+\overline{\mathrm{T}}$ than during $\overline{\mathrm{L}}+\mathrm{T},(\mathrm{p}<.01)$.

None of the interactions between stimulus conditions and any of the remaining variables reached significance.

\section{DISCUSSION}

The schedule of reinforcement was the same for subjects in both groups during the discriminative stimulus intervals. However, the discriminative stimuli themselves were different for the two groups during the first part of the experiment (i.e., $\mathrm{L}+\mathrm{T}$ in Group 1 and either $L+\bar{T}$ or $\bar{L}+T$ in Group 2 ). We expected that if any response rate differences existed between the groups, such differences would be found during the discriminative stimulus intervals, but there were no such differences. Instead, the subjects in the two groups responded at different rates during extinction intervals when the stimulus in both groups was $\overline{\mathrm{L}}+\overline{\mathrm{T}}$. A result analagous to response summation would have been demonstrated if the Group 1 subjects had responded at a higher rate during $L+T$ than the Group 2 subjects had during either $L+\bar{T}$ or $\bar{L}+T$. However, the lower extinction rates of the Group 1 subjects, and the greater difference among their rates in reinforcement and extinction components of the schedule, may also be related to response summation.

There are two possible explanations for these results. The first is that the Group 1 discriminative stimulus was a simultaneous change in both light and tone, whereas the Group 2 stimulus was a change in only one of these stimuli. Such an explanation is essentially similar to Weiss's (1978) model of response summation within an individual subject. The second possibility is that the better discrimination of the Group 1 subjects was caused by the use of one discriminative stimulus, $\mathrm{L}+\mathrm{T}$, as opposed to the use of two discriminative stimuli, $L+\bar{T}$ and $\bar{L}+T$, in Group 2. There have been a number of studies that have shown that rats discriminated less accurately in mazes when more than one discriminative stimulus was used (Gardner \& Coate, 1965; Mandler, 1973; Mullins \& Winefield, 1979).

The abrupt increase in the rate at which the Group 1 subjects responded during $\overline{\mathrm{L}}+\overline{\mathrm{T}}$ when the additional discriminative stimuli were introduced may also have been related to the processes underlying response summation. These subjects had never been reinforced for responding when either light or tone were off during the first part of the experiment. Introduction of $L+\bar{T}$ and $\bar{L}+T$ as discriminative stimuli allowed the subjects to earn some reinforcements when either light or tone was off. Thus, the correlation between the presence or absence of light and tone, and the probability of reinforcement, were reduced. Under those conditions, a model of response summation based on discriminative processes could predict either an increase in $\overline{\mathrm{L}}+\overline{\mathrm{T}}$ rates, or a decrease in $\mathrm{L}+\mathrm{T}$ rates. The former effect was observed.

The second part of the experiment showed that subjects in both groups responded at higher mean rates during $L+T$ than during either of the other discriminative stimuli. That result is, by definition, an example of response summation. However, it is difficult to see how response summation could have been based on the response strength of the individual component stimuli for the subjects in Group 1. They had never responded in the presence of the component stimuli until the testing procedure began.

The absence of any interaction between groups and stimuli or any higher order interaction among stimuli, groups, and days precludes the possibility that response summation developed for the subjects in Group 1 only after they had been exposed to the individual stimuli for some time. Response summation appeared immediately among the subjects of both groups and was equally strong in each. These data clearly indicate that summation need not be the result of previous conditioning to the components of the compound stimulus.

It also implies that the $\mathrm{L}+\mathrm{T}$ compound to which the Group 1 subjects responded during the first 12 sessions, had no properties that were unique to the stimulus compound. Apparently, the subjects responded to $\mathrm{L}+\mathrm{T}$ as if it were nothing more than the combination of the light and tone components.

\section{REFERENCES}

Gardner, R. A., \& Conte, W. B. Reward versus nonreward in a simultaneous discrimination. Journal of Experimental Psychology, 1965, 69, 579-582.

Kehoe, E. J., \& Gormezano, I. Configuration and combination laws in conditioning with compound stimuli. Psychological Bulletin, 1980, 87, 351-378.

Konorski, J. Conditioned reflexes and neuron organization. Cambridge: Cambridge University Press, 1948. 
Mandler, J. M. Multiple stimulus discrimination learning. III. What is learned? Quarterly Journal of Experimental Psychology, 1973, 25, 112-123.

Meltzer, D., \& Freeman, B. J. Maintenance of response summation under conditions of minimum stimulus intensity. Psychonomic Science, 1971, 22, 287-289.

Mullins, G. P., \& Winefield, A. H. The relative importance of responses to $\mathrm{S}+$ and $\mathrm{S}-$ in simultaneous discrimination learning. Quarterly Journal of Experimental Psychology, 1979, 31, 329-338.

Pavlov, I. P. [Conditioned reflexes. An investigation of the physiological activity of the higher nervous activity of the cerebral cortex] (G. V. Anrep, trans.). London: Oxford University Press, 1927.

WEISS, S. J. Summation of response strengths instrumentally conditioned to stimuli in different sensory modalities. Journal of Experimental Psychology, 1964, 68, 151-155.

WEISS, S. J. Discriminated response and incentive processes in operant conditioning: A two factor model of stimulus control. Journal of the Experimental Analysis of Behavior, 1978, 30, 361-381.

(Manuscript received for publication June 17, 1983.) 